\title{
The Level of Participation of the Bicycle Community in Improving Self-Esteem
}

\author{
Yusuf Dwi Meirianto*, Komarudin Komarudin, Mulyana Mulyana \\ Sport Education Program, Postgraduate School \\ Universitas Pendidikan Indonesia \\ Bandung, Indonesia \\ *yusufdm97@gmail.com, komarudin_pko@upi.edu
}

\begin{abstract}
This study aims to determine the relationship of the level of participation of the bicycle community in the city of Bandung in improving self-esteem, the sample of this study was fifty people. Sampling is done by using Stratified Proportional Random Sampling technique. This research method is quantitative descriptive method, with correlational research type. The instruments used were Sport Motivation Scale-6 (SMS-6) and Self Esteem Rating Scale (SERS). The results of this study indicate that the level of participation has a positive and significant relationship in improving self-esteem in the bicycle community in the city of Bandung. The implementation for development of live that it's The level of participation in sports activities, especially cycling, can provide a relationship to the quality of social interactions, therefore the conditions of these activities can provide benefits not only physical health, but social health, Participation in the bicycle community also provides a relationship about how as an individual can recognize himself and others through self-esteem. To form self-esteem, the learning process must pay attention to psychological aspects in order to realize learning and education goals, and Giving knowledge to policy makers about the importance of sports activities that involve community participation in bicycle use. The conclusion of this study is the level of participation has a positive and significant relationship with the quality of improving self-esteem.
\end{abstract}

Keywords-level of participation; self esteem; bicycle community

\section{INTRODUCTION}

Participation in sports can provide psychological and physiological benefits [1]. "Sport participation and physical activity protect against and reduce symptoms of depression and anxiety, delay cognitive decline, increase self-esteem and feelings of energy, and contribute to the overall quality of life". Through sports participation and physical activity can protect, reduce symptoms of depression, anxiety, delay cognitive decline, increase self-esteem, feelings of energy, and contribute to quality of life. The physical and psychosocial benefits of sports participation are well documented with evidence that sports play an important role in promoting health and wellbeing among children and adults [2]. There is some evidence that physical health and well-being can be increased through participation in sports, which are not necessarily competitive, aggressive, or simply 'sweaty'. Many people participate in sports with a variety of reasons and choices, and it is also possible to compete, relax, to get away from daily activities, maybe also for social reasons. People participate in sports that is to distinguish themselves and to reflect their status and prestige [3].

Cycling is an activity that involves physical and psychosocial. Cycling is one of the most popular sports among men and women [4]. This is because cycling is an activity that can be done outdoors, relax, feel the natural atmosphere and recreation. Bicycling and walking are clearly popular activities, whether for sport, recreation, exercise, or simply for relaxation and enjoyment of the outdoors [5]. Sport participation, physical activity and social capital have been at the center of academic and policy interest for their positive effects on mental health [6]. Through sports participation, physical activity and social capital have become centers of academic interest and policies in providing positive effects on mental health. Active participation in physical activity promotes the development of positive habits, enhances healthy lifestyles, have implications for health and provide psychological health benefits [7]. Today many people experience a lack of exercise activity, resulting in increased obesity in the community [6]. People who work long hours and are limited by intense time, hardly possible intensive exercise such as cycling, but may prefer fitness, they assume that participation in cycling, swimming and running is an unorganized activity. Cycling activities are most preferred and most often practiced because they allow one to participate, practice, and recreation. This sport, almost regardless of time and place, therefore this sport can be done almost anywhere and anytime [8]. Seeing the phenomenon in Indonesia recently noted, that activities whose physical activities are presented in an 'environmentally friendly' nuance are prioritized. Nowadays, many physical activities carried out through cycling, because cycling can play a role in social, health, pollution reduction environment [9]. In the practice of cycling, it certainly has various objectives, has a variety of time ranges, has a rhythm, expresses certain styles and modes, and utilizes technology, and passes through various types of space [10].

But in reality, the sports participation rate in Indonesia is still very low, according to data from the Central Statistics Agency, in 2015, the number of people who regularly exercise has not reached one third of the total population, only 27.61 
percent of Indonesians exercise at least once a week. This means that out of 100 Indonesians aged 10 years and over, only about 28 people actively participate in sports activities, while 72 others do not exercise regularly. This phenomenon shows that the participation of Indonesian people in exercising in general is still relatively low.

The diverse bicycle community consists of cyclists aiming for bicycle messengers, hill climbers, recreation in rural, urban and commuter [10]. Each community has its own schedule in its activities and the community is considering recruiting its members, in this case such as similarities in bicycle type, social class, racial background. therefore, the opportunity to participate with the community is limited. These considerations come from a sense of recognition both from yourself and other individuals, this comes from one's self esteem. As for the conditions within the community itself, often members in the community show themselves to be recognized, dominate the conversation when they gather with their community. make things that are separation from some people who are considered different from the type or type of bicycle they use. Individuals with a higher income are more likely to participate in sports [11]. Individuals with high income are more likely to participate in sports activities, this is to show inequality in sports participation between various groups in society [12]. As in previous studies, found that age, gender, social class, and racial background influence sports participation and disability.

Cycling activities carried out by the bicycle community in the city of Bandung, have become a lifestyle for the community, in one week the bicycle community already has routine activities, such as the routine agenda held by the community Selasa Khiji, Bandung MTB, and Bike to Work. From these routine activities they have their own goals, both with the purpose of sports, going to work, and recreation. Cycling is not just a lifestyle but a part of life because cycling will make the body healthy, have social aspects and protect the environment [13]. In the results of other studies found that participation in sports helps develop self-esteem and improve goal orientation [14]. Cycling can also significantly improve psychological well-being in terms of reducing stress. This also provides a good opportunity to socialize with people such as exchanging ideas, information and social networking. By having a social network, this refers to the relationship between individuals or groups and can be considered as an element of social structure. Formal social networks include those developed through formal organizations such as voluntary organizations and associations, and this type of network, especially the center of conception of social capital [15]. Joining a local bicycle club is a good way to meet new people and friends. This study aims to complement in previous studies, namely how the relationship of sports participation level cycling social interaction and self-esteem are interrelated.

\section{METHOD}

\section{A. Participant}

The population in this study was the bicycle community in Bandung City with a total of 150 people. This sampling technique is to use stratified proportional random sampling [16].
The sample in this study is a road bike, commuter bike, and mountain bike community which amounts to 50 people.

\section{B. Procedurs}

The research method used in this research is descriptive quantitative research method. This research was conducted for one month carried out in May 2018.

In this study the authors gave instructions, objectives and research interests to the research subjects, namely members of the bicycle community. Then the initial observations, filling the participation scale, and the self-esteem scale were carried out. After the data is obtained, data processing is done to see the relationship between the level of participation of the bicycle community in the formation of self-esteem.

\section{Instruments}

The instrument in this study is using Sport Motivation Scale-6 [17]. aims to assess one's motivational orientation in participating in sports. Self-Monitoring Scale is a 25-item social interaction assessment instrument, which presents a selfreport in the basic measure of social/ communication skills. Self-esteem Rating Scale (SERS) [18].

\section{RESULT AND DISCUSSION}

Participation plays a role in building an individual's involvement with other individuals, this is based on the dimension of Self-esteem. Based on the results of field research found that the level of participation has a high and significant correlation with Self-esteem. Self-esteem is often interpreted as self-esteem or self-confidence; this is related to the process of a person's interaction with the social environment in which the individual is located. Self-esteem is closely related to feeling worthy, worthy, valuable, capable and useful for individuals. Expert opinion regarding Self-esteem basically has the same meaning. Lutan argues that "Self-Esteem is self-acceptance, by oneself that we are worthy, valuable, capable, and useful no matter what is, is or is going to happen. The growing feeling of being able and being valuable is at the core of the notion of self-esteem. The connection between the level of participation and Self-esteem in the bicycle community can be based on the ability or desire of individuals to be able to carry out activities that are appropriate, valuable, fun, and complete challenges. Based on its geographical location, the city of Bandung is an area surrounded by mountains, this is an attraction for cyclists to be able to participate in the community, or individuals. This is in line with the opinion of Coopersmith that "Self-esteem is a personal judgment of worthiness that is expressed in terms of the individual holding toward himself". The purpose of the expression is that Self-esteem is an assessment of oneself regarding evaluations related to self-acceptance. This evaluation will show how an individual evaluates to himself, recognition that he has an ability or not, as an individual who is successful or not shows how far the individual feels he is important and valuable. Therefore, from cycling activities, with the presence of fellow cyclists, there will be a sense to show ability to others. self-esteem improved with participation in physical activity regardless of physical activity type [19]. therefore, self-esteem can be increased through participating in 
physical activity. In this study the authors found that showing themselves in completing the challenges of cycling routes or competing in community groups is influenced by Self-esteem. Both self-concept and self-esteem have been shown to be positively related to participation in physical activity, and to have an inverse relationship with depressive symptoms. This shows a positive relationship between participation in physical activity and self-esteem. That this study found results from participation in sports helped develop self-esteem and improved goal orientation [14]. After the author reviews, it turns out that the results of research and supporting theory, proved that indeed the level of participation has a correlation with Self-esteem in the bicycle community in Bandung.

\section{CONCLUSION}

Participation plays a role in building the involvement of an individual with other individuals, this is based on the dimension of Self-esteem The relationship between the level of participation with Self-esteem in the bicycle community can be based on the ability or desire of individuals to be able to do an activity that is appropriate, valuable, fun, and complete challenges . Based on the results of this study that there is a positive and significant correlation between the level of participation with self-esteem in the bicycle community in the city of Bandung with a correlation value of 0.979 is in a very high relationship. Therefore, from cycling activities, with the presence of fellow cyclists there will be a sense to show ability to others, in this study found that showing themselves in completing the challenges of cycling routes or competing in groups is influenced by Self-esteem.

From Table I, above is known the correlation of the level of participation with self-esteem is at the Pearson correlation $(\mathrm{r})=$ 0.979 and sig. $=0,000<0,05$ so the relationship is significant, this means there is a relationship between the level of participation in improving self-esteem. Based on Table 1, that with a correlation value of 0.979 is in the meaning of a very high relationship.

TABLE I. RESUlTS OF THE CORRELATION LEVEL OF PARTICIPATION LEVEL IN IMPROVING SELF ESTEEM

\begin{tabular}{|l|l|l|}
\hline \multicolumn{1}{|c|}{ Variable } & \multicolumn{2}{|c|}{ Self-esteem Correlation } \\
\hline \multirow{4}{*}{ Participation } & Pearson Correlation & 0.979 \\
\cline { 2 - 3 } & Sig. (2-tailed) & 0.000 \\
\cline { 2 - 3 } & $\mathrm{N}$ & 50 \\
\hline
\end{tabular}

\section{ACKNOWLEDGMENT}

This work was supported by the Universitas Pendidikan Indonesia, Bandung Government, and Selasa Kahiji Cycling Community.
We also thank the Associate Editor and anonymous reviewers for their thoughtful comments during the review process. Finally, we are grateful to ATLANTIS PRESS and Proceedings of the $3^{\text {rd }}$ ICSSHPE 2018.

\section{REFERENCES}

[1] D. Ahmed, W. King, Y. Ho, R.L. Van Niekerk, T. Morris, M. Elayaraja, K. Lee, and E. Randles, The self-esteem, goal orientation, and healthrelated physical fitness of active and inactive adolescent students, pp. 114, 2017.

[2] Hoffman, Associated with Enhanced Physical, no. March, pp. 149-161, 2005

[3] D. Booth and J. Loy, "Sport , Status , and Style," J. Sport Hist. Rev., vol 30, pp. 1-26, 1999.

[4] E. Leslie, E. Cerin, C.J. Gore, A.S. George, A. Bauman, and N. Owen, Gender, Age, and Educational- Attainment Differences in Australian Adults 'Participation in Vigorous Sporting and Fitness Activities, pp. 377-388, 2004.

[5] Turner, Federal Highway Administration University Course on Bicycle and Pedestrian Transportation, no. July, 2006.

[6] J. Coakley, Assessing the sociology of sport: On cultural sensibilities and the great sport myth, vol. 2000, 2015.

[7] W.L. Haskell, I. Lee, R.R. Pate, K.E. Powell, and S.N. Blair, "Physical Activity and Public Health: Updated Recommendation for Adults From the American College of Sports Medicine and the American Heart Association," vol. 39, pp. 1423-1434, 2007.

[8] C. Breuer, K. Hallmann, P. Wicker, C. Breuer, K. Hallmann, and P. Wicker, Determinants of sport participation in different sports Determinants of sport participation in different sports, no. August 2013 , pp. 37-41, 2011.

[9] F. Cochoy, J. Hagberg, and R. Canu, The forgotten role of pedestrian transportation in urban life: Insights from a visual comparative archaeology Gothenburg and, vol. 52, no. 12, pp. 2267-2286, 2015.

[10] M. Cook and T. Edensor, Mobilities Cycling through Dark Space: Apprehending Landscape Otherwise, no. May 2015, pp. 37-41, 2014.

[11] T. Berger, I.E., O’Reilly, N., Parent, M.M., Se'guin, B. and Hernandez, "Determinants of sport participation among Canadian adolescents," J. Sport Manag. Rev., vol. 3, no. 11, pp. 277-307, 2008.

[12] B.R. Humphreys and J.E. Ruseski, Participation In Physical Activity And Government Spending On Parks And Recreation, 2007.

[13] B. Fincham, Bicycle messengers and the road to freedom, Editor. Board Sociol. Rev., vol. 2, pp. 208-222, 2006.

[14] R.J. "Sonstroem, Exercise and self-esteem", Exerc. Sport Sci. Rev., vol. 12, pp. 123-155, 1984.

[15] F.E. Baum and A.M. Ziersch, Social capital, vol. 57, pp. 320-323, 2003.

[16] J.R. Fraenkel, N.E. Wallen, and H.H. Hyun, Bibliyografisi Bulunacak, vol. 53, no. 9. 2013

[17] L.G. Pelletier, K.M. Tuson, M.S. Fortier, R.J. Vallerand, N.M. Brikre, M.R. Blais, and Q.B. Montrcal, Toward a New Measure of Intrinsic Motivation, Extrinsic Motivation, and Amotivation in Sports: The Sport Motivation Scale ( SMS ), pp. 35-53, 1995.

[18] W.R. Nugent and J.W. Thomas, Research on Social Work Practice, 1993.

[19] D. Scully, J. Kremer, M.M. Meade, R. Graham, and K. Dudgeon, Physical exercise and psychological well being: a critical review, no. March, pp. 111-120, 1998. 